\title{
Testing Novel New Drip Emitter with Variable Diameters for a Variable Rate Drip Irrigation
}

\author{
Hadi A. AL-agele ${ }^{1,2, * \mathbb{C}}$, Lloyd Nackley ${ }^{3}{ }^{(-)}$and Chad Higgins ${ }^{1}$ \\ 1 Department of Biological and Ecological Engineering, College of Agricultural Science, Oregon State University, \\ Corvallis, OR 97331, USA; chad.higgins@oregonstate.edu \\ 2 Department of Soil and Water Resource, College of Agriculture, Al-Qasim Green University, \\ Al-Qasim District 964, Babylon 51013, Iraq \\ 3 North Willamette Research and Extension Center, Department of Horticulture, College of Agricultural Science, \\ Oregon State University, Aurora, OR 97201, USA; lloyd.nackley@oregonstate.edu \\ * Correspondence: alageleh@oregonstate.edu
}

check for updates

Citation: AL-agele, H.A.; Nackley, L.; Higgins, C. Testing Novel New Drip Emitter with Variable Diameters for a Variable Rate Drip Irrigation. Agriculture 2021, 11, 87. https:// doi.org/10.3390/agriculture11020087

Received: 10 December 2020

Accepted: 17 January 2021

Published: 20 January 2021

Publisher's Note: MDPI stays neutral with regard to jurisdictional claims in published maps and institutional affiliations.

Copyright: (c) 2021 by the authors. Licensee MDPI, Basel, Switzerland. This article is an open access article distributed under the terms and conditions of the Creative Commons Attribution (CC BY) license (https:// creativecommons.org/licenses/by/ $4.0 /)$.

\begin{abstract}
This research presents a new variable rate drip irrigation (VRDI) emitter design that can monitor individual water drops. Conventional drip systems cannot monitor the individual water flow rate per emitter. Application uniformity for conventional drip emitters can be decreased by clogged emitters, irregular emitter orifices, and decreases in pressure. A VRDI emitter can overcome the irrigation challenges in the field by increasing water application uniformity for each plant and reducing water losses. Flow rate is affected by the diameter of the delivery pipe and the pressure of the irrigation delivery system. This study compares the volumetric water flow rate for conventional drip emitters and new VRDI emitters with variable diameters inner ( $1 \mathrm{~mm}, 1.2 \mathrm{~mm}, 1.4 \mathrm{~mm}$, and $1.6 \mathrm{~mm})$ and outside ( $3 \mathrm{~mm}, 3.5 \mathrm{~mm}, 4 \mathrm{~mm}$, and $4.5 \mathrm{~mm}$ ) with three pressures $(34 \mathrm{kPa}, 69 \mathrm{kPa}$, and $103 \mathrm{kPa})$. The tests revealed that the new VRDI emitter had flow rates that increased as the operating pressure increased similar to a conventional drip tube. The flow rate was slightly increased in the VRDI with pressure, but even this increase did not show large changes in the flow rate. The flow rate of the conventional drip tube was $88 \%$ larger than the VRDI emitter for all pressures $(p<0.05)$. However, operating pressure did not affect the drop sizes at the VRDI emitter, but the generalized linear mixed models (GLM) results show that volume per drop was impacted by the outside diameter of the VRDI outlet $(p<0.05)$. The interaction between the inner and outside diameter was also significant at $p<0.01$, and the interaction between outside diameter and pressure was statistically significant at $p<0.01$. The electronic components used to control our VRDI emitter are readily compatible with off-the-shelf data telemetry solutions; thus, each emitter could be controlled remotely and relay data to a centralized data repository or decision-maker, and a plurality of these emitters could be used to enable full-field scale VRDI.
\end{abstract}

Keywords: drip irrigation; flow rate; pressure compensation

\section{Introduction}

In recent decades, drip irrigation technology has become more popular around the world. In California (2010), drip irrigation has covered $\sim 40 \%$ of irrigated land [1]. Drip irrigation may increase water application efficiency and decreases water losses [2]. Further, water use efficiency and plant growth (the number of leaves, leaf area, plant height, and matter production) increases significantly with drip irrigation compared to flood irrigation [3]. In another study, subsurface drip irrigation treatments had significantly increased yield; improved crop quality; reduced water application; and reduced agronomic costs for weed control, fertilization, and tillage [4].

One aspect that reduces the full potential of drip irrigation is the potential for nonuniform water application for field-scale drip irrigation as a result of pressure changes within the drip line [5]. Energy losses within the drip line or elevation changes from uneven 
ground alter the pressure in the system. This pressure variability is addressed with pressure compensated emitters along the drip line [6]. These devices reduce the impact of, but do not eliminate, pressure variance [7].

Spatial variability and non-uniform irrigation application are problems for flood irrigation and conventional overhead and drip irrigation. Hydraulic design elements of each respective irrigation system such as field slope, pipe networks, nozzle geometries, and pump characteristics are linked with the cumulative volume of water applied. In overhead systems, this spatial variability has been addressed using variable-rate irrigation (VRI) [8,9]. Currently, there is not an equivalent VRI approach for drip irrigation in the marketplace. A recent patent was given for a segmented variable rate drip irrigation system using flow control valves to supply water for two horizontal pipes [10]. This system is promising but does not yet enable full control of the flow at each emitter. Two studies evaluated the potential benefits of field scale variable rate drip irrigation (VRDI) in wine grapes and found that precision irrigation with VRDI led to an increase in yield of $10 \%$ and $17 \%$ and an increase in water use efficiency of $17 \%$ and $20 \%$ [11,12]. VRDI studies in a Vineyards showed an increase in water use efficiency of $18 \%$ and $25 \%$ that did not lead to any changes in the total yield and product quality $[13,14]$. To enable full VRDI, each drip emitter inlet and/or outlet must be individually outfitted with a flow meter to monitor the flow, a valve to manipulate the flow, and a communication unit to relay the data, and a microprocessor to control everything. More advanced versions could incorporate localized sensors (humidity, soil moisture, temperature, $\mathrm{pH}$, rainfall, sap flow, dendrometers, or other observables) to automate irrigation control [15].

Recent advances in data telemetry, miniaturized valves, and electronic controllers have enabled greater control over drip irrigation systems. For example, an automated drip irrigation system that integrates soil moisture, temperature, and $\mathrm{pH}$ data in conjunction with an Arduino microcontroller to automate the irrigation system was successfully built [16]. Recently, a new drip emitter prototype that monitors the water applied [7] has created a pathway for full VRDI by controlling the size of and counting each drop that is emitted.

The study presented herein focuses on and extends the VRDI approach of [7]. Here, we assess the impact of hydraulic design elements (nozzle diameters) on the cumulative volume of water applied and potential maximum flow rates.

\section{Materials and Methods}

The VRDI system used in this experiment (Figure $1 \mathrm{a}, \mathrm{b}$ ) was a modified version of the system presented in detail in [7]. In brief: the emitter encapsulated and pierced an irrigation hose. Water was routed through tortuous path consisting of 20 microchannels in succession, each $2.0 \mathrm{~mm}$ high and $2.593 \mathrm{~mm}$ in width. The purpose of this element was to reduce the pressure and flow rate. Next, water was routed through a micro-solenoid (DC12V G 1/4" Electric Solenoid Valve N/C Feed for RO Water Air Quick Connector from eBay) before exiting a small nozzle. Drops were released from this orifice based on the force balance between gravity (pulling the drops down) and surface tension (pulling droplets upward). The net effect of this process created drops of consistent mass. Once the drops fell, they passed through a measurement chamber where the water briefly connected two electrical leads. A microcontroller maintained a running count of the drops and operated the solenoid valve to commence or halt the flow (Figure 1a). 


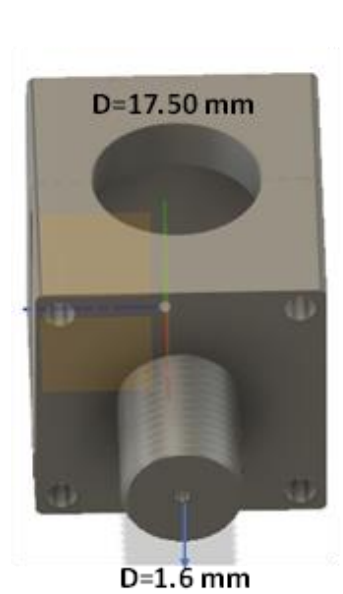

Connected with drip tube

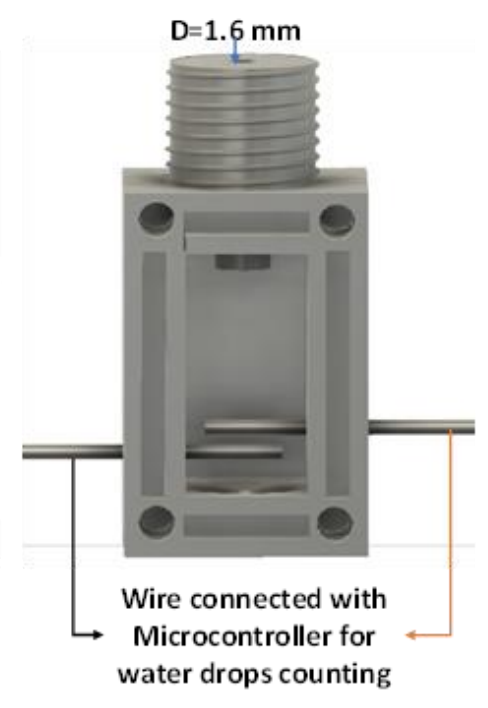

(a)

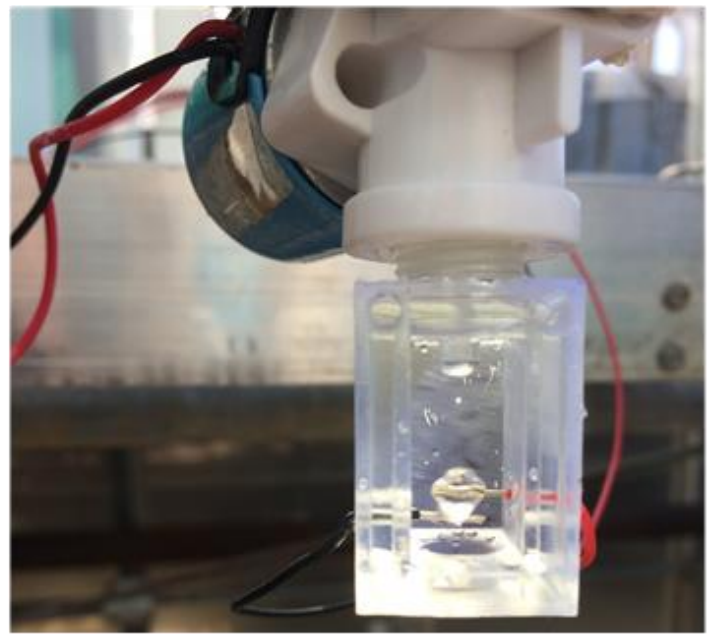

Drop completed electronic circle

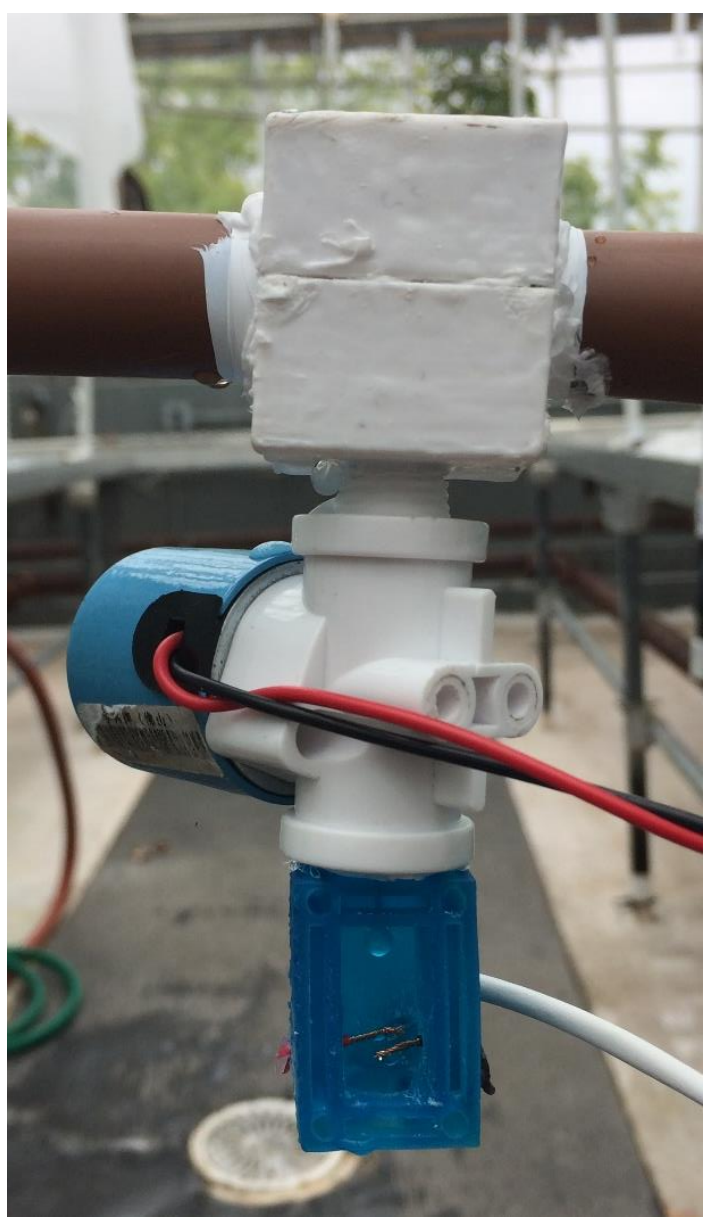

(b)

Figure 1. (a) New variable rate drip irrigation (VRDI) emitter design shows all the components. (b) VRDI drip emitter with $3 \mathrm{~mm}$ outer and $1 \mathrm{~mm}$ inner diameters. Emitters with all permutations of inner diameter $(1 \mathrm{~mm}, 1.2 \mathrm{~mm}, 1.4 \mathrm{~mm}$, and $1.6 \mathrm{~mm})$ and outside diameter $(3 \mathrm{~mm}, 3,5 \mathrm{~mm}, 4 \mathrm{~mm}$, and $4.5 \mathrm{~mm})$ were constructed and tested. 
A modified version was constructed for this manuscript. The modified version was designed such that the variable inner and outside diameter of the emitter nozzle could be evaluated in the lab with a factorial experimental design. A critical design question is whether the inner or outer diameter of this nozzle form the contact line for surface tension and subsequently determine the drop mass and volume. The test was done for four inside diameters (ID) $1 \mathrm{~mm}, 1.2 \mathrm{~mm}, 1.4 \mathrm{~mm}$, and $1.6 \mathrm{~mm}$ with $(+/-0.08 \mathrm{~mm})$, with four outside diameters (OD) $3 \mathrm{~mm}, 3.5 \mathrm{~mm}, 4 \mathrm{~mm}$, and $4.5 \mathrm{~mm}(+/-0.08 \mathrm{~mm}$ ) (Table 1).

Table 1. Lab experiment for conventional drip emitter with new drip emitter.

\begin{tabular}{ccccc}
\hline ID $(\mathbf{m m})$ & OD $\mathbf{( m m )}$ & Pressure (kPa) & Replicates & $\begin{array}{c}\text { Time for Each } \\
\text { Replicate (min) }\end{array}$ \\
\hline Conventional & & $34,69,103$ & 6 & 10 \\
1 & $3,3.5,4,4.5$ & $34,69,103$ & 6 & 10 \\
1.2 & $3,3.5,4,4.5$ & $34,69,103$ & 6 & 10 \\
1.4 & $3,3.5,4,4.5$ & $34,69,103$ & 6 & 10 \\
1.6 & $3,3.5,4,4.5$ & $34,69,103$ & 6 & 10 \\
\hline
\end{tabular}

\subsection{Lab Test}

A test of the VRDI prototypes was performed at Oregon State University, Corvallis, OR, USA. Conventional drip tube (Earthline Brown pipe, DIG, Vista, CA, USA) served as a comparator to the new VRDI design. The pressures within the systems were regulated by using pressure regulator (Stettler support company, Salem, OR, USA), and tests were performed for three operating pressures: $34 \mathrm{kPa}, 69 \mathrm{kPa}$, and $103 \mathrm{kPa}$, with error $+/-7 \mathrm{kPa}$ or (1 psi). Note that the minimum recommended operating pressure for the commercial system is $69 \mathrm{kPa}$. Our hypothesis is that the VRDI emitter can operate at these lower pressures which would result in energy savings. All systems and prototypes were operated for 10 min with six replicates (Table 1). The operating time and number of drops were recorded by using Arduino Nano basic microcontroller (Figure 1b). The total water volume applied was measured with a graduated cylinder.

\subsection{Data Analysis}

\subsubsection{Conventional Drip Data}

We performed single-factor ANOVA on groups of conventional drip data and Tukey tests with post hoc comparisons for mean differences $\alpha=0.05$.

\subsubsection{VRI Drip Emitter}

We used generalized linear mixed models (GLM) nested analysis, with each independent variable as the nesting variable (variable pressures, inner and outside diameter), to test for differences between each version of the variable rate drip irrigation emitter [17]. The GLM test is used to check how the volume of applied water was affected by the independent variables. Post hoc comparisons for mean differences were with Tukey tests with $\alpha=0.05$. We performed a separate test to compare the collective impacts of all the variables on applied water volume. Three independent variables were included in the experiment: (1) pressure, which has four levels $(34 \mathrm{kPa}, 69 \mathrm{kPa}$, and $103 \mathrm{kPa})$; (2) four inner diameters ( $1 \mathrm{~mm}, 1.2 \mathrm{~mm}, 1.4 \mathrm{~mm}$, and $1.6 \mathrm{~mm})$; and (3) four outside diameters $(3 \mathrm{~mm}$, $3.5 \mathrm{~mm}, 4 \mathrm{~mm}$, and $4.5 \mathrm{~mm}$ ) with the commercial drip emitter. Table 2 shows the mean $(\mu)$ and standard deviation (SD) values for commercial drip emitter with new drip emitter of every independent variable. 
Table 2. Descriptive statistics of flow rate commercial drip emitter with new drip emitter for the lab experiment.

\begin{tabular}{|c|c|c|c|c|}
\hline & & \multicolumn{3}{|c|}{ Pressure (kPa) } \\
\hline \multirow{2}{*}{\multicolumn{2}{|c|}{ Drip Emitter Type }} & 34 & 69 & 103 \\
\hline & & \multicolumn{3}{|c|}{ Flow Rate $\mu \pm \mathrm{SD}\left(\mathrm{cm}^{3} / \mathrm{min}\right)$} \\
\hline $\begin{array}{l}\text { Inner Diameter } \\
(\mathrm{mm})\end{array}$ & $\begin{array}{l}\text { Outside Diameter } \\
(\mathrm{mm})\end{array}$ & & & \\
\hline \multirow{5}{*}{1} & 3 & $2.50 \pm 2.11$ & $4.97 \pm 0.25$ & $6.87 \pm 0.10$ \\
\hline & 3.5 & $2.11 \pm 0.00$ & $3.53 \pm 0.07$ & $4.12 \pm 0.32$ \\
\hline & 4 & $2.98 \pm 0.06$ & $4.49 \pm 0.05$ & $5.98 \pm 0.23$ \\
\hline & 4.5 & $2.13 \pm 0.07$ & $4.19 \pm 0.18$ & $5.75 \pm 0.16$ \\
\hline & 3 & $3.06 \pm 0.12$ & $4.62 \pm 0.07$ & $6.58 \pm 0.10$ \\
\hline \multirow{3}{*}{1.2} & 3.5 & $1.82 \pm 0.10$ & $3.52 \pm 0.37$ & $4.34 \pm 0.09$ \\
\hline & 4 & $2.01 \pm 0.24$ & $4.35 \pm 0.06$ & $5.79 \pm 0.14$ \\
\hline & 4.5 & $1.83 \pm 0.05$ & $4.14 \pm 0.10$ & $5.48 \pm 0.16$ \\
\hline \multirow{4}{*}{1.4} & 3 & $2.85 \pm 0.28$ & $4.82 \pm 0.11$ & $6.32 \pm 0.12$ \\
\hline & 3.5 & $2.11 \pm 0.17$ & $4.11 \pm 0.12$ & $5.55 \pm 0.38$ \\
\hline & 4 & $2.73 \pm 0.03$ & $4.42 \pm 0.19$ & $6.12 \pm 0.04$ \\
\hline & 4.5 & $1.92 \pm 0.09$ & $3.55 \pm 0.13$ & $5.21 \pm 0.04$ \\
\hline \multirow{4}{*}{1.6} & 3 & $1.97 \pm 0.10$ & $3.46 \pm 0.07$ & $4.30 \pm 0.26$ \\
\hline & 3.5 & $2.59 \pm 0.42$ & $4.91 \pm 0.13$ & $6.05 \pm 0.15$ \\
\hline & 4 & $2.00 \pm 0.06$ & $4.30 \pm 0.09$ & $5.69 \pm 0.28$ \\
\hline & 4.5 & $1.94 \pm 0.03$ & $3.85 \pm 0.08$ & $4.87 \pm 0.25$ \\
\hline \multicolumn{2}{|c|}{ Commercial drip tube } & $20.89 \pm 1.43$ & $37.61 \pm 1.13$ & $45.43 \pm 0.98$ \\
\hline
\end{tabular}

\section{Result}

\subsection{Conventional Drip}

The ANOVA results showed a statistically significant relationship between flow rate and pressure $(p<0.01)$. The interaction terms between the independent variables were also investigated. In the case of statistically significant effects, custom post hoc contrasts were performed for multiple comparisons using Tukey's test. The interaction of $34 \mathrm{kPa}$ and $69 \mathrm{kPa}, 34 \mathrm{kPa}$, and $103 \mathrm{kPa}$, and $103 \mathrm{kPa}$ and $69 \mathrm{kPa}$, were statistically significant ( $p$-value $<0.01$ for all) (Figure 2).

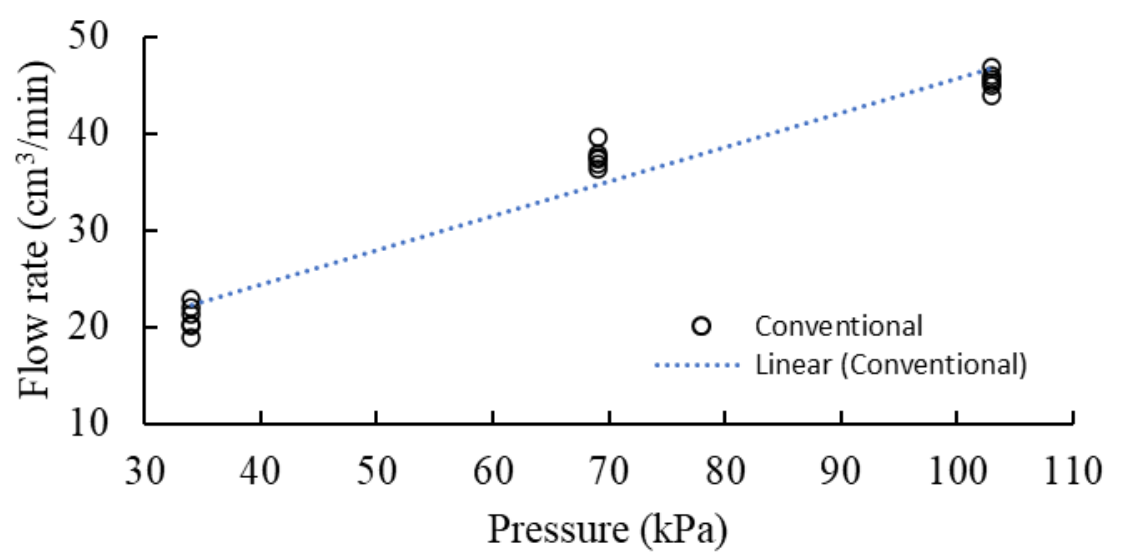

Figure 2. Relationship between water flow and pressure with conventional drip irrigation.

\subsection{VRDI Emitter Design Test}

The results of the GLM nested to analysis are shown in Table 3. The GLM analysis shows that the outside diameter (GLM nested) and inner diameter with outside diameter were statistically significant $(p<0.01)$ for all levels, but the relationship between pressure applied water volume was not statistically significant $(p=0.06)$ : Table 3 and Figures 3 and 4 . 
Table 3. Summary of generalized linear mixed model (GLM) nested for the lab testing experiment.

\begin{tabular}{cccccc}
\hline $\begin{array}{c}\text { Source of } \\
\text { Variance }\end{array}$ & $\begin{array}{c}\text { Degree of } \\
\text { Freedom (DF) }\end{array}$ & $\begin{array}{c}\text { Adjusted Sum of } \\
\text { Squares (Adj SS) }\end{array}$ & $\begin{array}{c}\text { Adjusted Mean } \\
\text { Squares (Adj MS) }\end{array}$ & $\begin{array}{c}\text { F- } \\
\text { Value }\end{array}$ & $p$-Value \\
\hline Pressure [kPa] & 2 & $6.60 \times 10^{-5}$ & $3.30 \times 10^{-5}$ & 2.89 & 0.057 \\
OD [mm] & 3 & $2.82 \times 10^{-3}$ & $9.38 \times 10^{-4}$ & 82.31 & 0 \\
ID(OD) [mm] & 12 & $1.22 \times 10^{-3}$ & $1.01 \times 10^{-4}$ & 8.89 & 0 \\
Error & 270 & $3.08 \times 10^{-3}$ & $1.10 \times 10^{-5}$ & & \\
Lack-of-Fit & 30 & $4.97 \times 10^{-4}$ & $1.70 \times 10^{-5}$ & 1.54 & 0.041 \\
Pure Error & 240 & $2.58 \times 10^{-3}$ & $1.10 \times 10^{-5}$ & & \\
Total & 287 & $1.38 \times 10^{-2}$ & & & \\
\hline
\end{tabular}

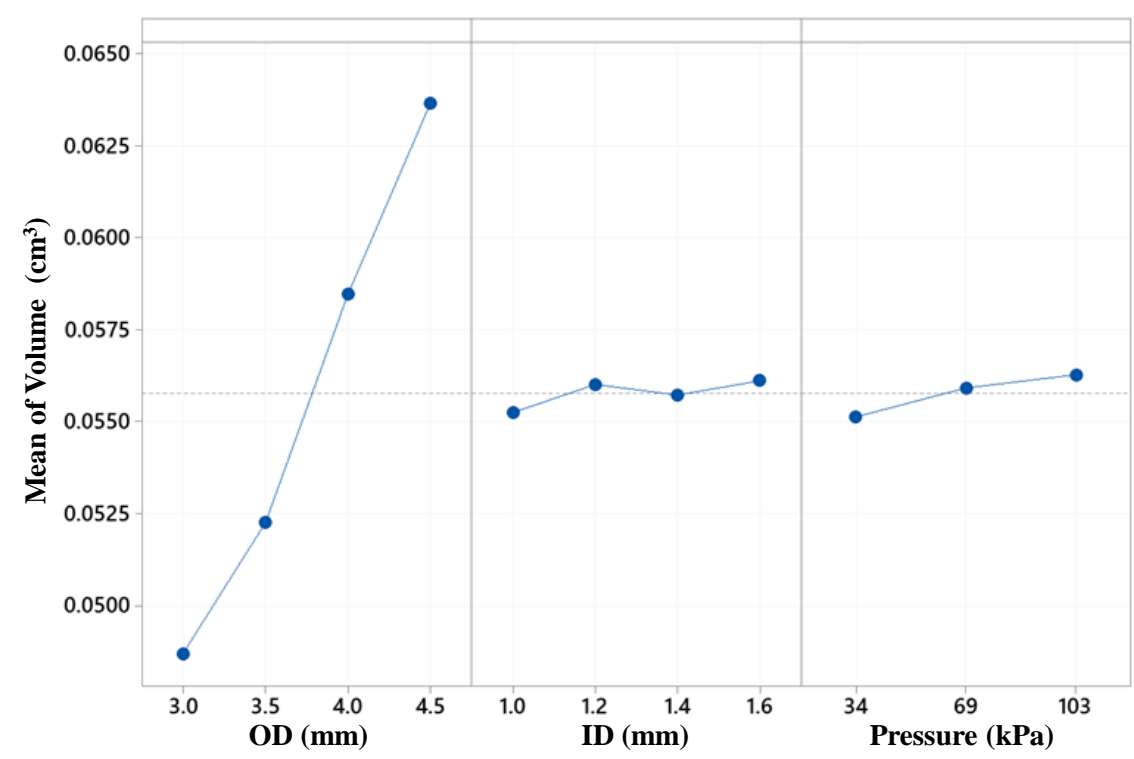

Figure 3. Mean of volume per drop related to the outside diameter, inner diameter, and pressure.

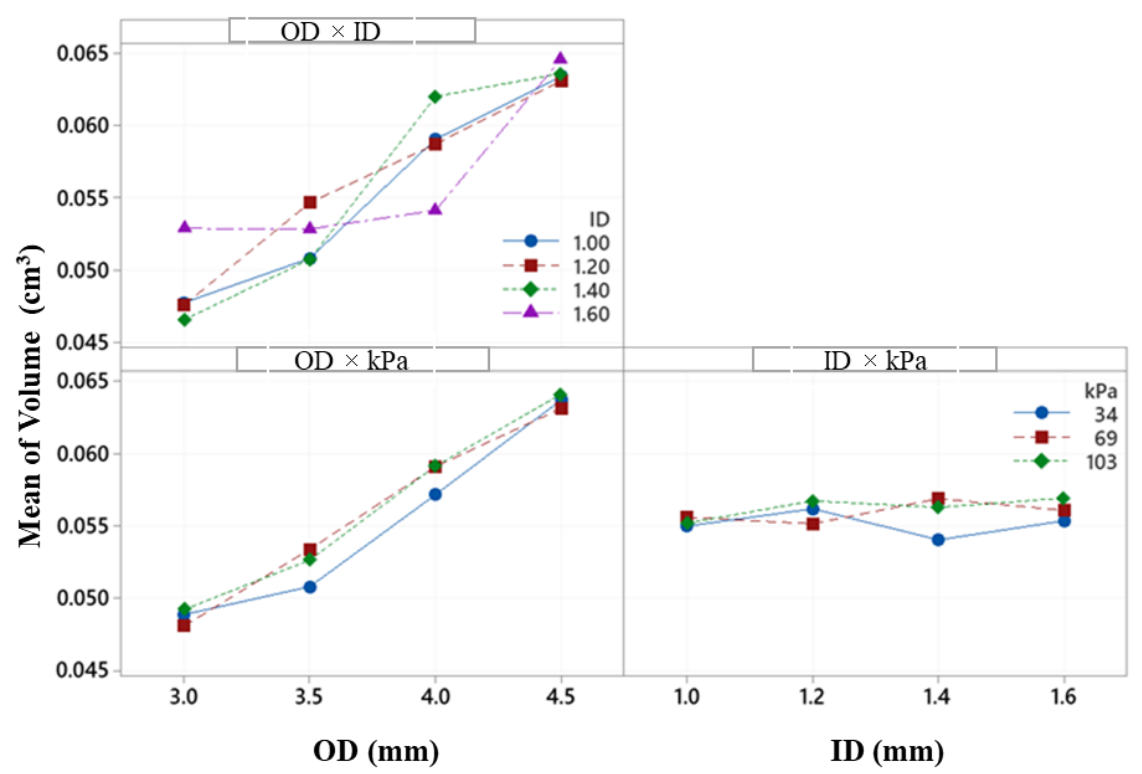

Figure 4. Two-way interactions on mean of volume/drop for pressure, outside diameter, and inner diameter.

Estimations of the relationship between $34 \mathrm{kPa}$ and $69 \mathrm{kPa}, 103 \mathrm{kPa}$ and $34 \mathrm{kPa}$, and $103 \mathrm{kPa}$ and $69 \mathrm{kPa}$ were tested with a Tukey pairwise comparison. Statistically significant $(p<0.05)$ relationships were found for $103 \mathrm{kPa}$ and $34 \mathrm{kPa}$ with Tukey pairwise 
comparisons for lab testing experiment, but the $34 \mathrm{kPa}$ and $69 \mathrm{kPa}$, and $103 \mathrm{kPa}$ and $69 \mathrm{kPa}$, were not statistically significant $(p=0.05)$. Additionally, estimations of the relationship water volume per drop between nozzle designs with $3.5 \mathrm{~mm}$ and $3.0 \mathrm{~mm}, 4.0 \mathrm{~mm}$ and $3.0 \mathrm{~mm}, 4.5 \mathrm{~mm}$ and $3.0 \mathrm{~mm}, 4.0 \mathrm{~mm}$ and $3.5 \mathrm{~mm}, 4.5 \mathrm{~mm}$ and $3.5 \mathrm{~mm}$, and $4.5 \mathrm{~mm}$ and $4.0 \mathrm{~mm}$ used Tukey pairwise comparisons to find the relationship. Outside diameters were statistically significant $(p<0.01)$, and Tukey pairwise comparisons were used for lab testing experiment.

\section{Discussion}

Typically, irrigation practice is to operate the drip system for a set amount of time and precision irrigation relies on a known, constant flow rate applied during the operational time. Variations in pressure affected the volumetric water flow rate in the conventional tube, and this variability could have led to reduced control over application uniformity under conventional, time-duration-based irrigation applications. In contrast, the GLM nested analysis showed no significant relationship between applied water volume and pressure for the VRDI emitters. As pressure does not to contribute to variance in water volume, we infer that the VRDI emitters can be operated at lower pressures. Further, the feedback control aspect of the system enables water managers to target watering amounts to specific locations, or potentially apply uniformly. Therefore, the new VRDI system could be used to increase application uniformity or respond to spatially variable irrigation demands.

The outside diameter of the emitter nozzle was positively correlated to the volume per drop in VRDI design, but the inner diameter showed no significant effect. We infer that the geometry of the nozzle exterior is such that the line of contact between the water and the nozzle is formed on the nozzle's exterior, and that this contact line (of surface tension) determines the final drop volume. Thus, the emitter can be designed such that the desired drop volume is achieved by increasing (for larger drops) or decreasing (for smaller drops) the outer diameter of the nozzle. A full derivation of the hydraulic theory is presented in Al-agele and Higgins (under review). The VRDI system successfully allows for precision control of irrigation water across a wide range of pressures, and although the number of drops per minute increases as a function of pressure, the volume of each drop is not a function of pressure. The VRDI emitter has one advantage: that it can operate at much lower pressures and save energy; therefore, we included low pressure values, outside the range of the commercial line to challenge the new design.

\section{Conclusions}

A VRDI emitter prototype was tested with variations in diameter (inner and outside). The tests revealed that show the new VRDI emitter had flow rates that increased as the operating pressure increased similar to a conventional drip tube. The VRDI emitter has the advantage that it can operate at much lower pressures and save energy. The percentage water flow difference between the conventional drip tube and the VRDI emitter was more than $88 \%$ with all variation pressures. However, the pressure operation was not a function for drop sizes at the VRDI emitter. The results show that the flow rate was statically significant at $p<0.05$ with increasing pressure in conventional drip tubes and VRDI. Additionally, the GLM nested results show that volume per drop was not significant with pressure and inner diameter at $p<0.05$ but was statically significant at $p<0.05$ with the outside diameter for VRDI emitter. In addition, the interaction between the inner and outside diameter showed significance at $p<0.01$ and the interaction between outside diameter was statistically significant at $p<0.01$. The electronic components used to control our VRDI prototype emitter are readily compatible with off-the-shelf data telemetry solutions; thus, each emitter could be controlled remotely and send data back to a centralized data repository or decision-maker, and a plurality of these emitters could be used to enable full-field scale VRDI. 
Author Contributions: Conceptualization, C.H. and H.A.A.-a.; methodology, H.A.A.-a.; software, H.A.A.-a.; validation, H.A.A.-a.; formal analysis, C.H. and H.A.A.-a.; investigation, H.A.A.-a.; resources, C.H.; data curation, H.A.A.-a.; writing-original draft preparation, H.A.A.-a. and C.H.; writing-review and editing, H.A.A.-a., C.H. and L.N.; visualization, C.H. and H.A.A.-a.; supervision, C.H. and L.N.; project administration, C.H.; funding acquisition, C.H. All authors have read and agreed to the published version of the manuscript.

Funding: This research was funded by US National Science Foundation NSF-GEO 1740082 and NSF- GEO 1712532.

Data Availability Statement: Data attached.

Acknowledgments: The work was supported by Al-Qasim Green University and the Ministry of Higher Education and Scientific Research in Iraq through a government scholarship. Partial funding was provided by NSF-GEO 1740082. The authors would like to thank Kyle Proctor for reviewing a paper and also Greyston Brady, Pre-Elect and Computer Engineer; Luke Goertzen and Bao Nguyen, coding developers at Opens Lab, BEE for assistance on code development, sensor assembly, and 3-D printing at Oregon State University for their help during the laboratory tests.

Conflicts of Interest: The authors declare no conflict of interest.

\section{References}

1. Taylor, R.; Zilberman, D. The Diffusion of Process Innovation: The Case of Drip Irrigation in California. In Proceedings of the 2015 Agricultural \& Applied Economics Association and Western Agricultural Economics Association Annual Meeting, San Francisco, CA, USA, 26-28 July 2015.

2. Van Der Kooij, S.; Zwarteveen, M.; Boesveld, H.; Kuper, M. The efficiency of drip irrigation unpacked. Agric. Water Manag. 2013, 123, 103-110. [CrossRef]

3. Chitra, R.; Havaraddi, R.M.; Subramanian, S.; Suresh, J. Effect of scheduling of drip irrigation on growth, yield and water use efficiency of turmeric (Curcuma longa L.) var. $\mathrm{CO}_{2}$. J. Spices Aromat. Crop. 2017, 26. [CrossRef]

4. Ayers, J.; Fulton, A.; Taylor, B. Subsurface drip irrigation in California-Here to stay? Agric. Water Manag. 2015, 157, 39-47. [CrossRef]

5. Fan, J.; Zhang, F.; Wu, L.; Yan, S.; Xiang, Y. Field evaluation of fertigation uniformity in drip irrigation system with pressure differential tank. Trans. Chin. Soc. Agric. Eng. 2016, 32, 96-101.

6. Chapin, R.D. Drip Irrigation System. U.S. Patent 4,626,130, 2 December 1986.

7. AL-agele, H.A.; Higgins, C.W. Electromechanical Drip Irrigation Device. U.S. Patent Application No. 17/073,814.

8. Perry, C.; Pocknee, S.; Hansen, O. A variable rate pivot irrigation control system. In Proceedings of the Fourth European Conference in Presicion Agriculture, Berlin, Germany, 15-19 June 2003; pp. 539-544.

9. Higgins, C.W.; Kelley, J.; Barr, C.; Hillyer, C. Determining the minimum management scale of a commercial variable-rate irrigation system. Trans. ASABE 2016, 59, 1671-1680.

10. Rodriguez, S.A.B.; Hamann, H.F.; Klein, L.; Schappert, M.A. Segmented Variable Rate Drip Irrigation. U.S. Patent 9,877,438, 30 January 2018.

11. Sanchez, L.; Sams, B.; Alsina, M.M.; Hinds, N.; Klein, L.J.; Dokoozlian, N. Improving vineyard water use efficiency and yield with variable rate irrigation in California. Adv. Anim. Biosci. 2017, 8, 574-577. [CrossRef]

12. Nadav, I.; Schweitzer, A. VRDI-Variable Rate Drip Irrigation in Vineyards. Adv. Anim. Biosci. 2017, 8, 569-573. [CrossRef]

13. Ortuani, B.; Facchi, A.; Mayer, A.; Bianchi, D.; Bianchi, A. Water Assessing the Effectiveness of Variable-Rate Drip Irrigation on Water Use Efficiency in a Vineyard in Northern Italy. Water 2019, 11, 1964. [CrossRef]

14. Ortuani, B.; Facchi, A.; Mayer, A.; Ronchetti, G.; Sona, G.; Brancadoro, L. Improvement of water use efficiency in an Italian vineyard through variable rate drip irrigation. In Proceedings of the 21st EGU General Assembly, EGU2019, Vienna, Austria, 7-12 April 2019.

15. Shilpa, A. Smart Drip Irrigation System. Int. J. Trend Sci. Res. Dev. 2018, 2, 1560-1565.

16. Parameswaran, G.; Sivaprasath, K. Arduino based smart drip irrigation system using Internet of Things. Int. J. Eng. Sci. 2016, 6,5518 .

17. O’Donnell, S.; Fiocca, K.; Campbell, M.; Bulova, S.; Zelanko, P.; Velinsky, D. Adult nutrition and reproductive physiology: A stable isotope analysis in a eusocial paper wasp (Mischocyttarus mastigophorus, Hymenoptera: Vespidae). Behav. Ecol. Sociobiol. 2018, 72, 86. [CrossRef] 